\title{
“BATIK MBANTULAN" DI SENTRA BATIK GIRILOYO DAN WIJIREJO BANTUL
}

\author{
I Made Sukanadi \\ Arif Suharson *)
}

\begin{abstract}
The study of batik in the batik centers of Giriloyo and Wijirejo Bantul is intended to develop the existing motifs of batik mbantulan and create new motifs while maintain the identity of batik mbantulan with its local-rich characteristics in Kabupaten Bantul. The development of batik mbantulan has undergone the rising and falling trend. To survive and develop artisans of batik mbantulan have to adapt themselves to the ongoing market preference through the improved characteristics of batik mbantulan.

It is necessary to explore the possible existing motifs of batik mbantulan that have brought up the batik center of Giriloyo and Wijirejo have. The motifs of batik mbantulan have to be reserved in the batik products through identification, diversification, and creation of new batik mbantulan motifs, Therefore, the new designs is expected to be more competitive in batik market and create the spirit of creativity and innovativeness among the artisans of batik mbantulan in the Batik Center of Giriloyo and Wijirejo Bantul.

The main obstacles that the artisans in the batik center of Giriloyo and Wijirejo have to face up is the meeting of consumers' orders with their new motifs. The artisans are not capable enough to create new designs through the development of mbantulan motifs and prefer to work on the present and general motifs of batik Yogyakarta. The study is expected to deal with the artisans' problem in creating new designs / motifs and improve their capacity to make new creative and innovative designs to meet consumers' desired standard. In turn, this will lead to a better economic prospect for the artisans of batik mbantulan in the batik center of Giriloyo and Wijirejo.
\end{abstract}

Key words: batik mbantulan, artisans, motifs

\section{PENDAHULUAN}

Batik yang ada di daerah Bantul konon keberadaannya bersamaan dengan berdirinya makam raja-raja Mataram di Imogiri pada abad ke 16. Seiring dengan berdirinya makam untuk raja-raja kraton Yogyakarta tersebut interaksi masyarakat dengan pihak kraton terjadi. Semasa kerajaan Mataram, Bantul dikenal dengan sebutan "Lipuro" yang termasuk salah satu wilayah dalam kekuasaan kerajaan Mataram Islam. Letak sebagian kerajaan Mataram Islam khususnya Pleret dan
Kotagede secara administrasi sekarang masuk wilayah Kabupaten Bantul. Sehingga budaya di wilayah Bantul masih sama dengan budaya kraton Yogyakarta, salah satunya adalah seni batik.

Keberadaan batik Bantul sering sekali disebut dengan sebutan batik mbantulan. Disebut demikian karena batik mbantulan memiliki ciri khas motif hasil pengembangan motif dari batik kraton dan diproses di wilayah Kabupaten Bantul. Motif batik mbantulan kebanyakan dibuat dengan ukuran besar dan geometris. Batik

\footnotetext{
*) I Made Sukanadi, Staf Pengajar Program studi Kriya Seni, Fakultas Seni Rupa, Institut Seni Indonesia Yogyakarta. Arif Suharson (arifkeramos@yahoo.com), Staf Pengajar Program studi Kriya Seni, Fakultas Seni Rupa, Institut Seni Indonesia Yogyakarta.
} 
yang berkembang di sentra tersebut termasuk dalam batik rakyat, dimana adanya peniruan pada corak batik di lingkungan kraton yang kaya akan simbolsimbol. Penduplikasian dilakukan sematamata karena posisi sosial dalam masyarakat ingin berpenampilan sebagaimana layaknya yang dikenakan oleh bangsawan.

Perjalanan batik mbantulan mengalami pasang surut dimana pengaruh kebudayaan lain, selera pasar/konsumen turut berperan besar terhadap perkembangan batik mbantulan di sentra batik Giriloyo dan Wijirejo Bantul. Hal ini terlihat pada kepeduliaan masyarakat penyangga budaya yaitu pengrajin batik mbantulan yang sudah mulai mengikuti selera pasar dan bergerak seolah meninggalkan ciri khas batik mbantulan itu sendiri. Ketidakmampuan pengrajin dalam menciptakan desain-desain baru batik mbantulan menjadi penyebab utama sehingga dalam kurun waktu 10 tahun terakhir ciri khas batik mbantulan kurang diminati oleh konsumen dan pengrajin. Pengrajin batik di sentra Giriloyo dan Wijirejo semakin banyak menerima pesanan konsumen yang menginginkan motif selain motif batik mbantulan.

Untuk mengetahui perjalanan dan motif batik mbantulan yang memiliki ciri khas dan pernah mencapai masa kejayaannya tentu tidak terlepas dari struktur sosial masyarakat penyangga dan pengaruh dari luar masyarakat pengrajin batik di sentra batik Giriloyo dan Wijirejo Bantul. Motif batik mbantulan yang menjadi ciri khas motif batik di Kabupaten Bantul harus tetap dipertahankan dan dijaga kelestariannya, agar tidak diakui oleh negara lain yang akan merugikan masyarakat batik terutama di sentra batik Giriloyo dan Wijirejo Bantul. Terkait dengan hal tersebut, maka harus dilakukan kajian terhadapnya secara ilmiah melalui kegiatan penelitian untuk menghasilkan motif-motif baru dengan teknik riningan.

\section{HASIL PENELITIAN}

Sejarah perkembangan batik di Yogyakarta terutama di daerah Bantul tidak dapat dipisahkan dengan kraton Yogyakarta sebagai pangkal tolak keberadaannya. Batik tradisional yang dihasilkan terbagi dalam dua kelompok besar yaitu batik kraton dan batik saudagaran. Disebut batik kraton karena batik tumbuh dan berkembang di lingkungan kraton dengan aturanaturan/pakem dengan dasar-dasar filsafat kebudayaan Jawa, yang mengacu pada nilai-nilai spiritual dan pemurnian diri, serta penuh dengan simbolisasi tanda dan makna. Tanda sering berhubungan dengan objek-objek yang menyerupai (icon). Keberadaannya memiliki hubungan sebab akibat (index) atau karena ikatan konvensional (symbol). Sedangkan batik saudagaran adalah batik yang tumbuh dan berkembang di luar dinding kraton, dimana keberadaannya tidak di bawah kendali kraton. Baik yang bersifat aturan, dominasi simbolik, dan filsafat kraton.

Daerah Bantul merupakan daerah potensi penghasil seni batik yang terkenal dengan sebutan batik mbantulan. Pada dasarnya batik mbantulan merupakan batik kraton Yogyakarta, karena sebagian besar motifnya mengambil dari motif-motif batik Yogyakarta. Disebut batik mbantulan karena batik tersebut diproduksi oleh masyarakat daerah Bantul yang letak wilayah geografisnya terletak di sebelah selatan Kraton Yogyakarta. Boleh dikatakan hasil produksi batik mbantulan merupakan hasil olah kreatif masyarakat Bantul yang mencoba menampilkan batik untuk dapat dipergunakan dalam kehidupan sehari-hari sebagai bahan sandang masyarakat sesuai tuntunan dari keraton Ngayogyakartahadiningrat. 
Maka dalam berbagai penciptaan motif atau karya seni batik yang adiluhung, masyarakat Bantul masih mengacu pada patronase-patronase budaya kraton yang masih dianggap menjadi panutan dan tuntunan. Juga timbul rasa prestise dalam masyarakat bahwa semua yang diciptakan yang mengadopsi budaya kraton akan memiliki nilai status budaya tinggi yang berarti akan membuat status sosial masyarakat Bantul menjadi tinggi pula. Penduplikasian dilakukan semata-mata karena posisi sosial dimana masyarakat ingin berpenampilan sebagaimana layaknya yang dikenakan oleh bangsawan.

Batik tersebut sengaja diproduksi oleh masyarakat Bantul untuk memenuhi kebutuhan sandang yang berbeda dengan batik yang dikenakan oleh orang keraton apalagi yang merupakan motif larangan yang tidak boleh dipergunakan oleh warga biasa akan tetapi hanya boleh dipergunakan oleh raja atau keluarga keraton. Maka muncullah istilah motif batik mbantulan yang mengambil motif dari keraton Yogyakarta dan dikombinasikan dengan motif hasil pengembangan masyarakat Bantul. Hasil pengembangan motif batik ini sering disebut pula sebagai batik rakyat, karena hasil motif batik mbantulan dapat dikenakan oleh rakyat biasa atau masyarakat luar kraton khususnya masyarakat Bantul. Beberapa wilayah di Bantul yang sampai saat ini masih memproduksi batik dan menjadi sentra batik diantaranya adalah: Imogiri, Pandak, Jetis, dan Pajangan.

Menurut informasi dari Pemda Bantul, batik Bantul merupakan batik yang juga bisa disebut sebagai batik petani atau batik rakyat. Istilah ini muncul karena batik memang dikerjakan oleh rakyat biasa yang notabene memiliki pekerjaan sebagai petani. Kegiatan membatik merupakan kegiatan sampingan menunggu hasil panen dan mengolah lahan pertanian. Poal-pola batik mbantulan terbagi menjadi 3 kelompok yaitu:

\section{Kelompok dengan pola batik asli kraton}

Kelompok ini biasa membuat batiknya meniru keterampilan putri dan abdi dalem penjaga atau pemelihara makam raja-raja Imogiri. Selain itu juga memodifikasi atau merubah pola sehingga tampil berbeda dengan pola aslinya bahkan dengan perkembangan komunikasi antar daerah melalui perdagangan oleh saudagar masuk pengaruh pola dari daerah lain. Kelompok pembatik ini meliputi Desa Wukirsari, Girirejo, dan Wijirejo.

\section{Kelompok batik kidulan}

Batik kidulan merupakan gabungan dari batik rakyat/batik petani dengan batik saudagaran, kelompok daerah yang membuat batik-batik dengan pola utama sebagai latar pola, seperti parang atau lereng, atau isen latar seperti galaran, gringsing, sisik, cecek kepyur yang dipadukan dengan ragam hias yang menggambarkan alam sekitar petani. Alam itu bisa berupa tumbuh-tumbuhan, bungabunga, burung, kupu-kupu, atau binatang lainnya. Kelompok batik kidulan atau rinen ini berada di daerah Sanden, Wijirejo, Pandak, dan sekitarnya.

\section{Kelompok batik nitik}

Kelompok batik nitik pada awalnya dikerjakan di daerah Pleret Wonokromo, tetapi sekarang banyak dikembangkan di daerah Kembangsongo dan Wijirejo. Pola nitik merupakan pola tiruan dari pola tenunan kain "Patola/Cinde" yang berasal dari Gujarat India. Kain tenun pola ini dibawa masuk ke Indonesia oleh pedagang Gujarat sekitar abad ke 17 melalui pantai utara Jawa. Perkembangan pola nitik ini menjadi berkembang dan kebanyakan diberi nama bunga, seperti kembang kentang, sekar kemuning, kembang kenanga, kembang kantil, kembang waru 
dan masih banyak lagi. Biasanya pola nitik juga digabung dengan pola lain seperti pola kawung, parang, garuda, keong, atau ceplok. Dari berbagai paduan gabungan pola tersebut muncul nama seperti nitik tambal, parang seling nitik, nitik kasatrian, nitik cakar ayam, tanjung gunung, dll.

Penelitian diawali dengan mendata batik khas Bantul dan mengklasifikasikannya untuk dilakukan pembuatan desain-desain alternatif. Dari beberapa desain-desain yang telah tercipta selanjutnya dipilih menjadi 18 desain yang

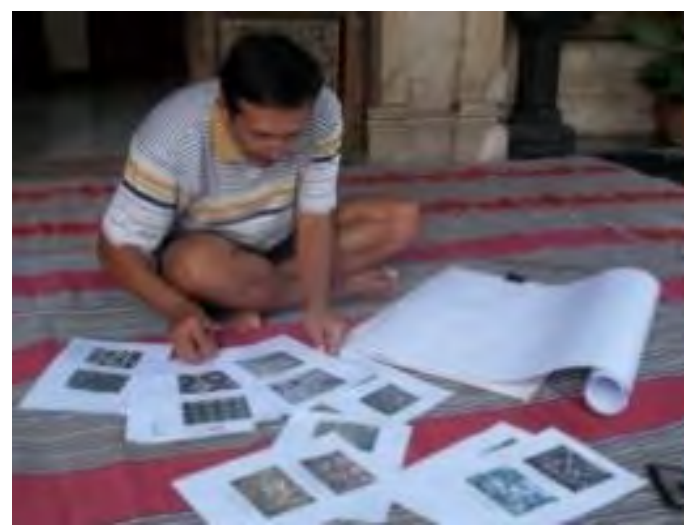

Gambar 1. Batik Bantul yang di dapat dari data lapangan selanjutnya diamati, diklasifikasi, dan selanjutnya dipilih untuk dilakukan pengembangan desain oleh Tim peneliti. menjadi master desain dan dipindahkan pada kain mori Primissima dan selanjutnya dilakukan pembatikan/pencantingan dengan diberi malam, diberi warna batik, dikebyok, dirining, diwarna kembali, dan finishing. Agar menadapatkan hasil yang maksimal dan memudahkan koordinasi peneliti dalam proses pembuatan batik, maka perwujudan desain pada kain batik dipusatkan di kelompok batik Sido Mukti di Giriloyo, Imogiri, Bantul. Berikut proses dan tahapan penelitian:

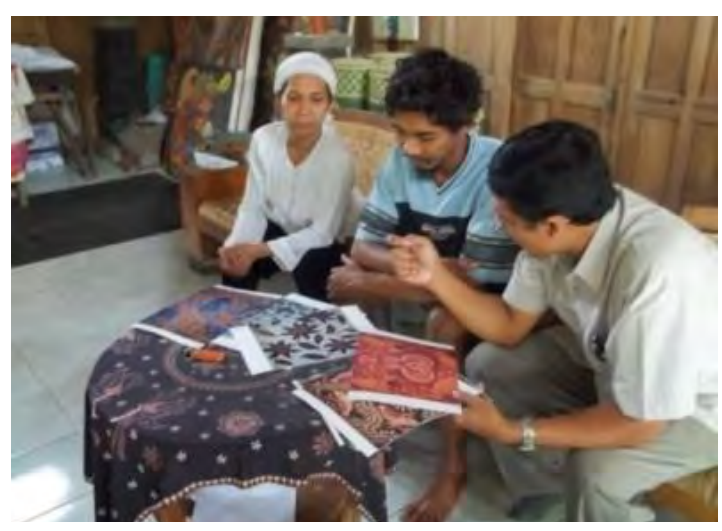

Gambar 2

Penjelasan desain baru kepada Kelompok Sido Mukti sebelum dilakukan pembatikan pada kain

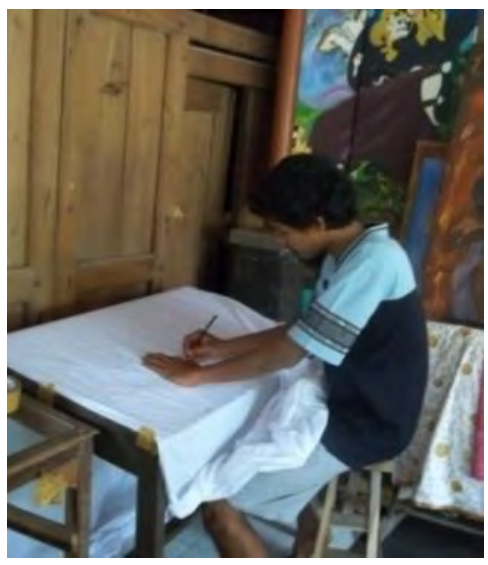

Gambar 3

Pemindahan motif pada kain sesuai desain/memola

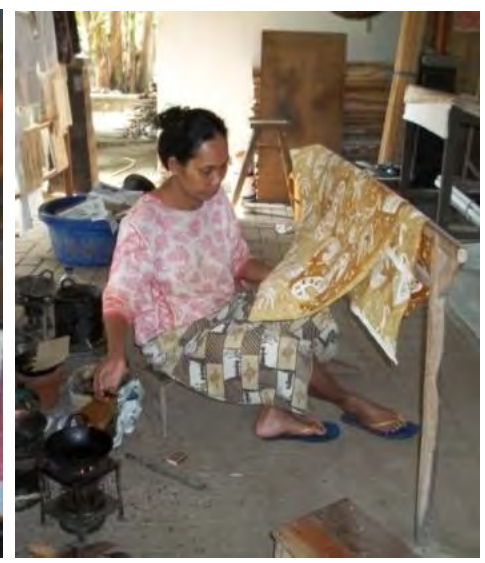

Gambar 4

Proses pelilinan malam/mencanting

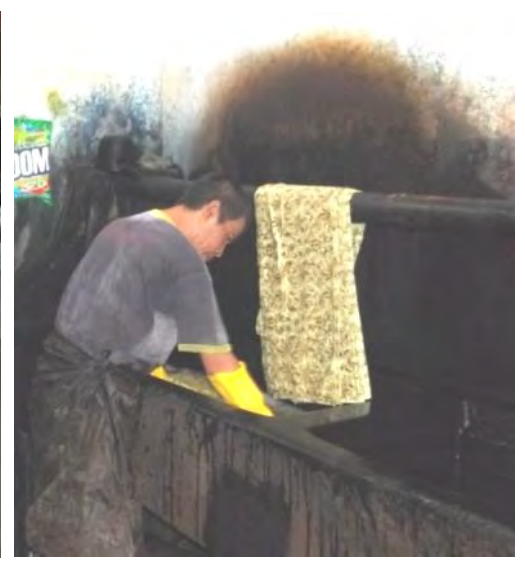

Gambar 5

Proses pewarnaan dengan Naptol 
Berikut desain-desain hasil penelitian dan pengembangan dari motif khas batik mbantulan sebagai master desain/prototipe:

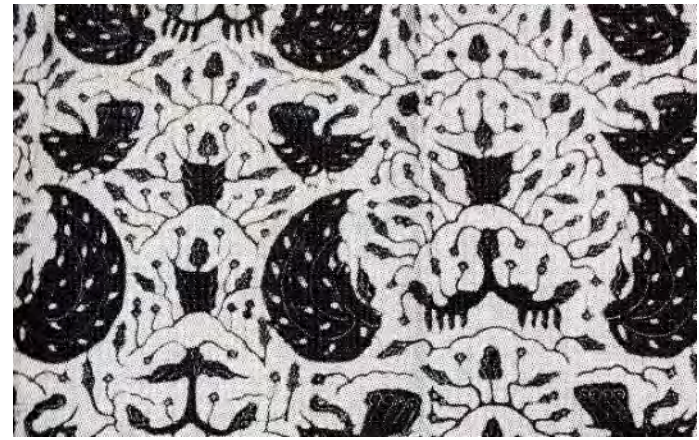

Gambar 6. Motif Siso Asih

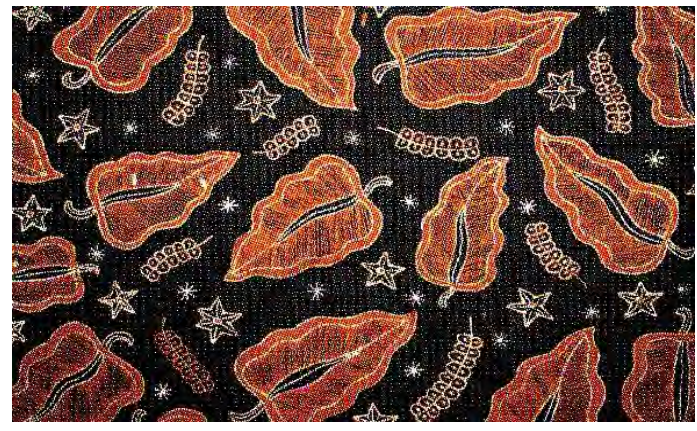

Gambar 7. Motif Daun Kopi

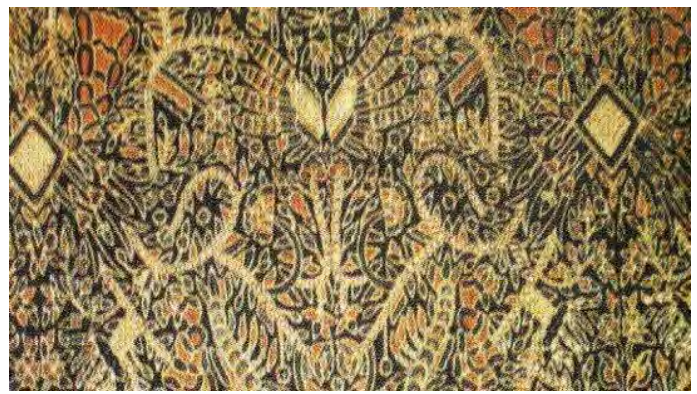

Gambar 9. Motif Lung Kangkung

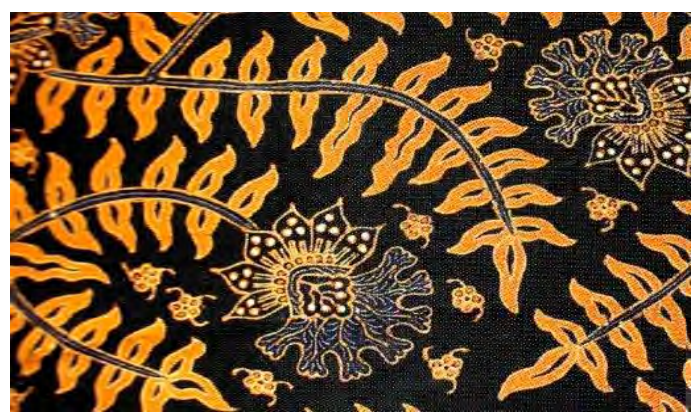

Gambar 10. Motif Lung-lungan

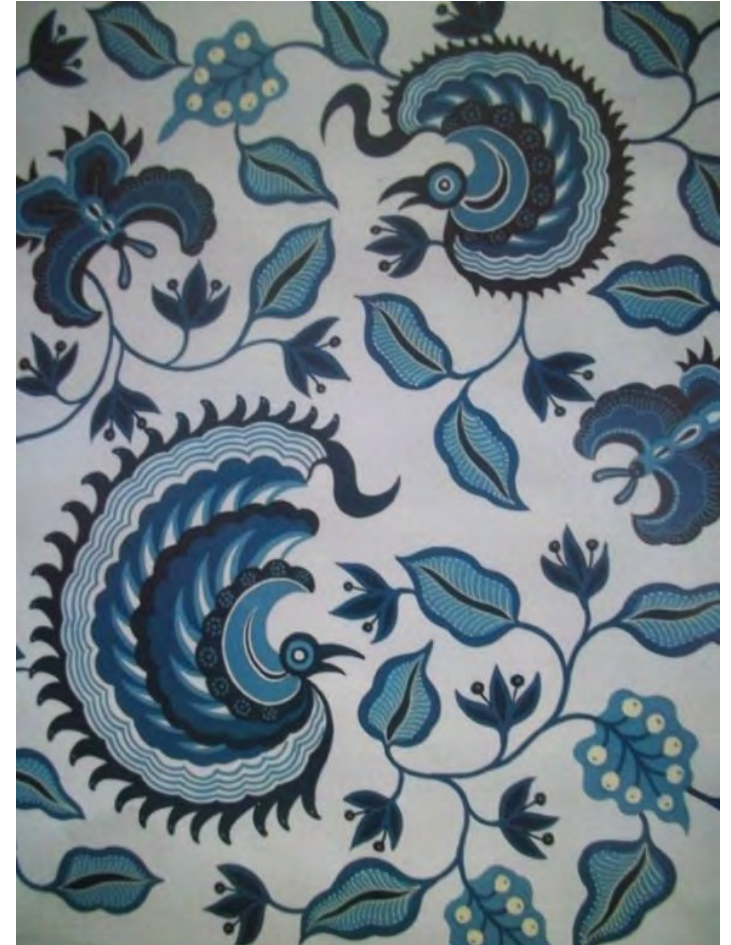

Gambar 8. Desain Batik Jadi ke-1

Merupakan hasil pengembangan dari motif batik Sido Asih dan motif daun kopi

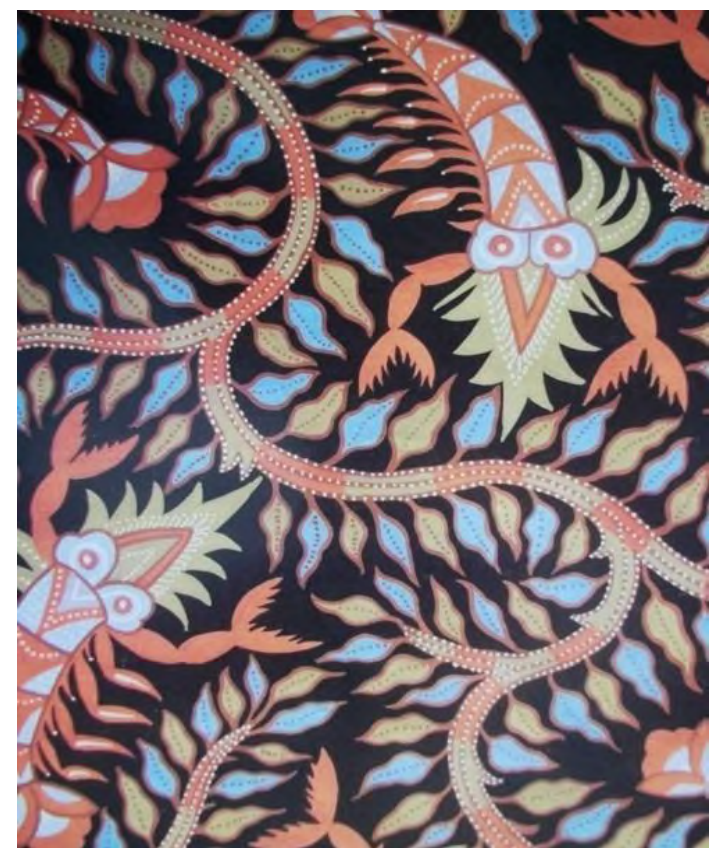

Gambar 11. Desain Batik Jadi ke-2 Merupakan hasil pengembangan dari motif batik Lung Kangkung dan motif Lung-lungan 


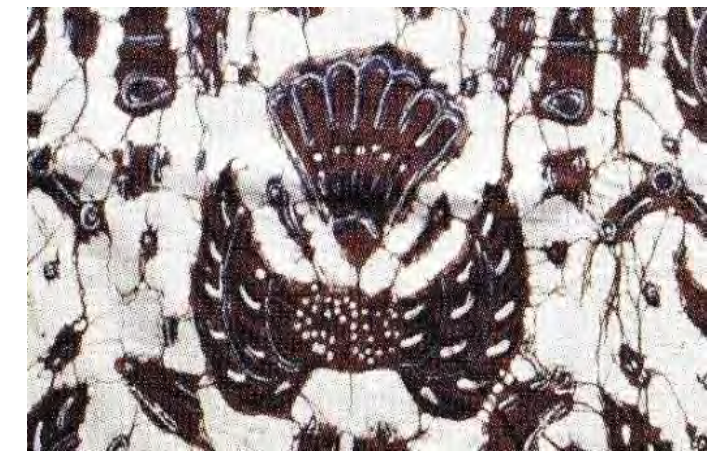

Gambar 12. Motif Sido Mukti

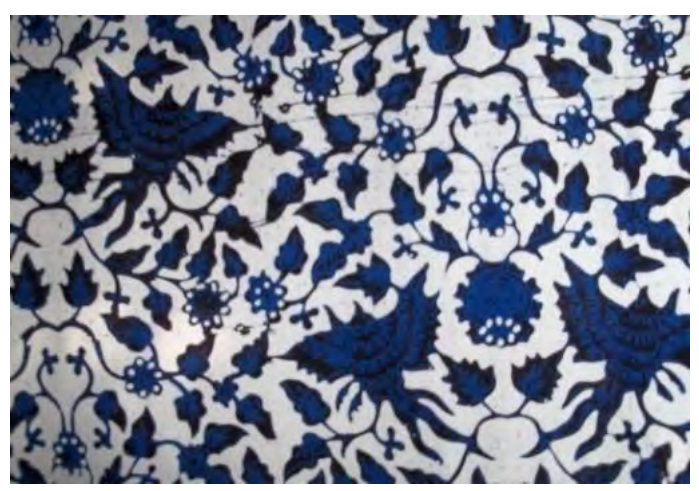

Gambar 13. Motif Burung Kembar

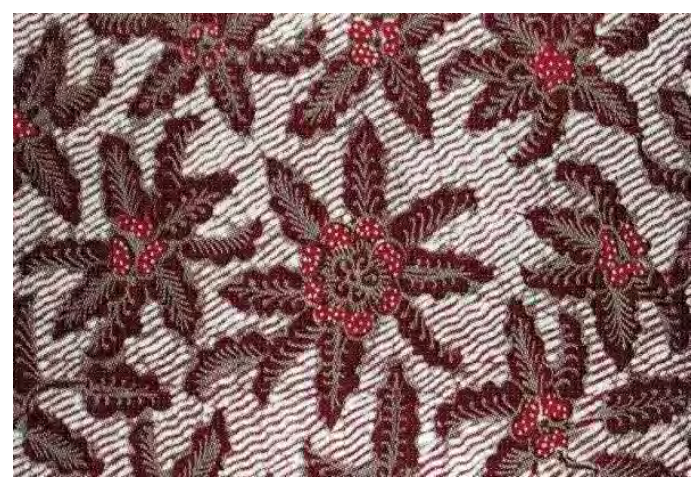

Gambar 15. Motif Kembang Latar Galaran

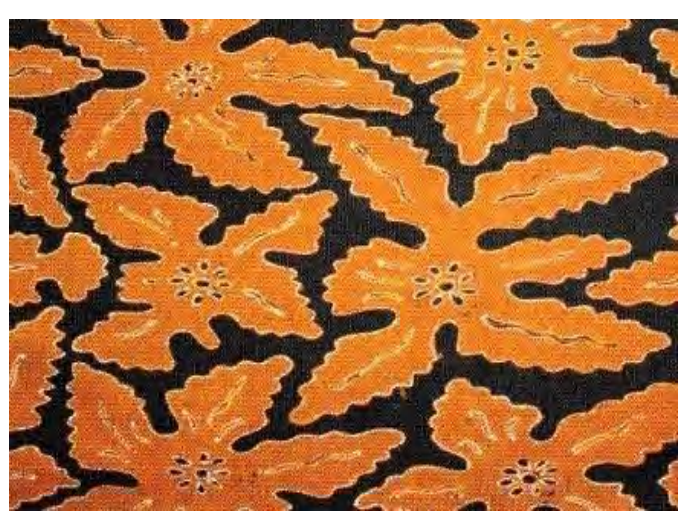

Gambar 16. Motif Jahe-jahean

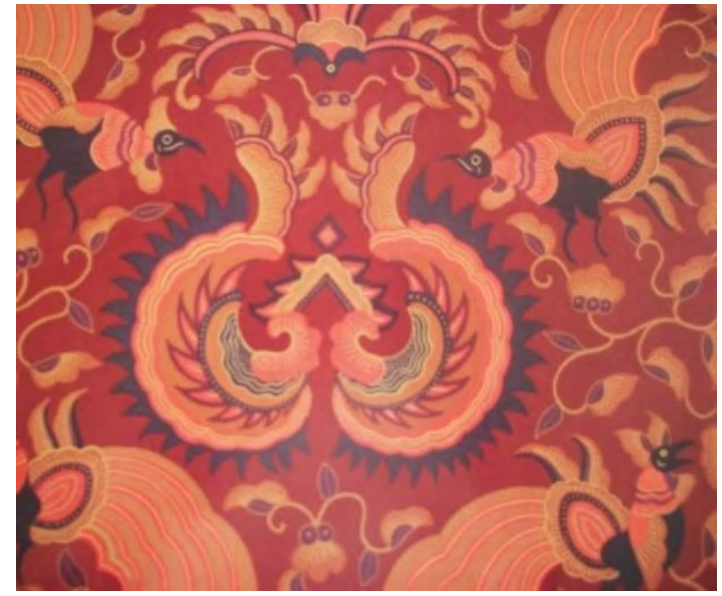

Gambar 14. Desain Batik Jadi ke-3

Merupakan hasil pengembangan dari motif batik Sido Mukti dan motif Burung Kembar

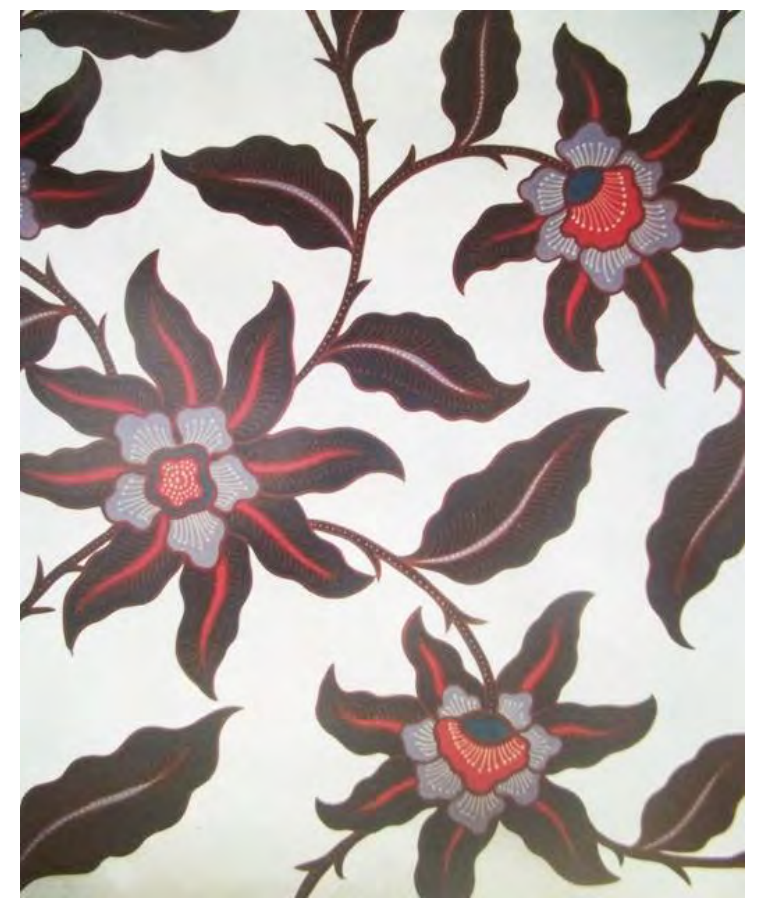

Gambar 17. Desain Batik Jadi ke-4

Merupakan hasil pengembangan dari motif batik Kembang Latar Galaran dan motif Jahe-jahean 


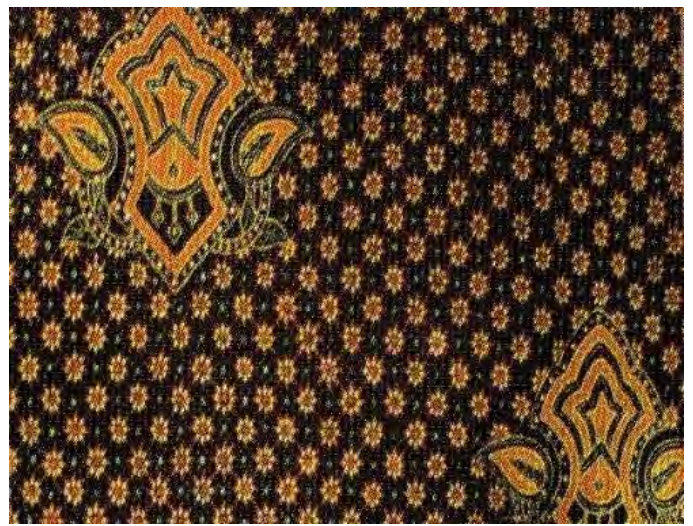

Gambar 18. Motif Truntum Mangkoro

Gambar 19. Desain Batik Jadi ke-5 Merupakan hasil pengembangan dari motif batik Truntum Mangkoro
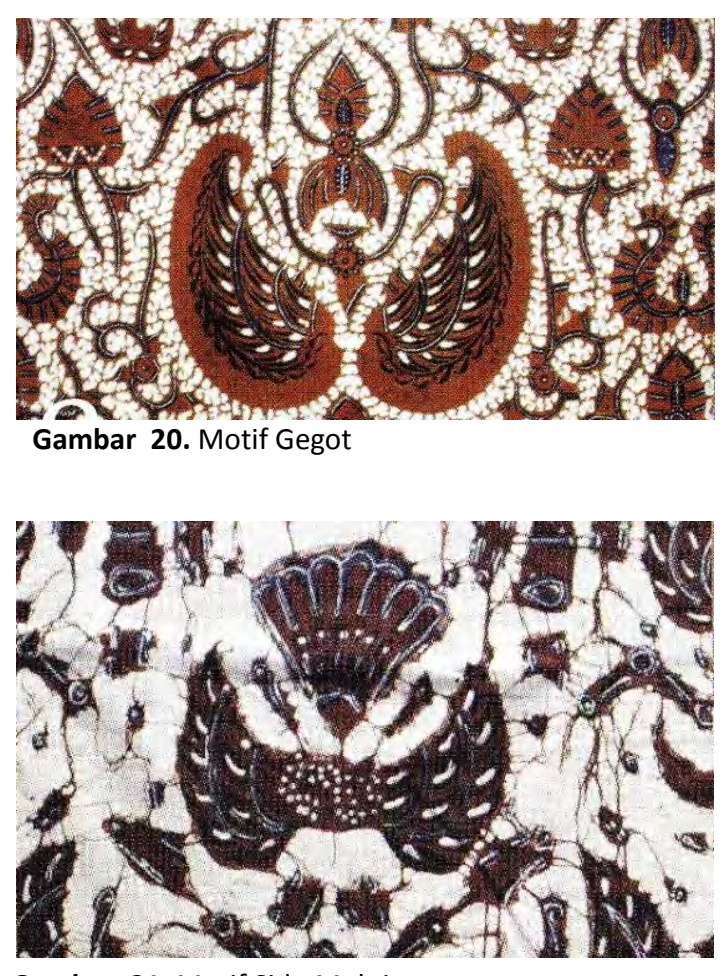

Gambar 21. Motif Sido Mukti
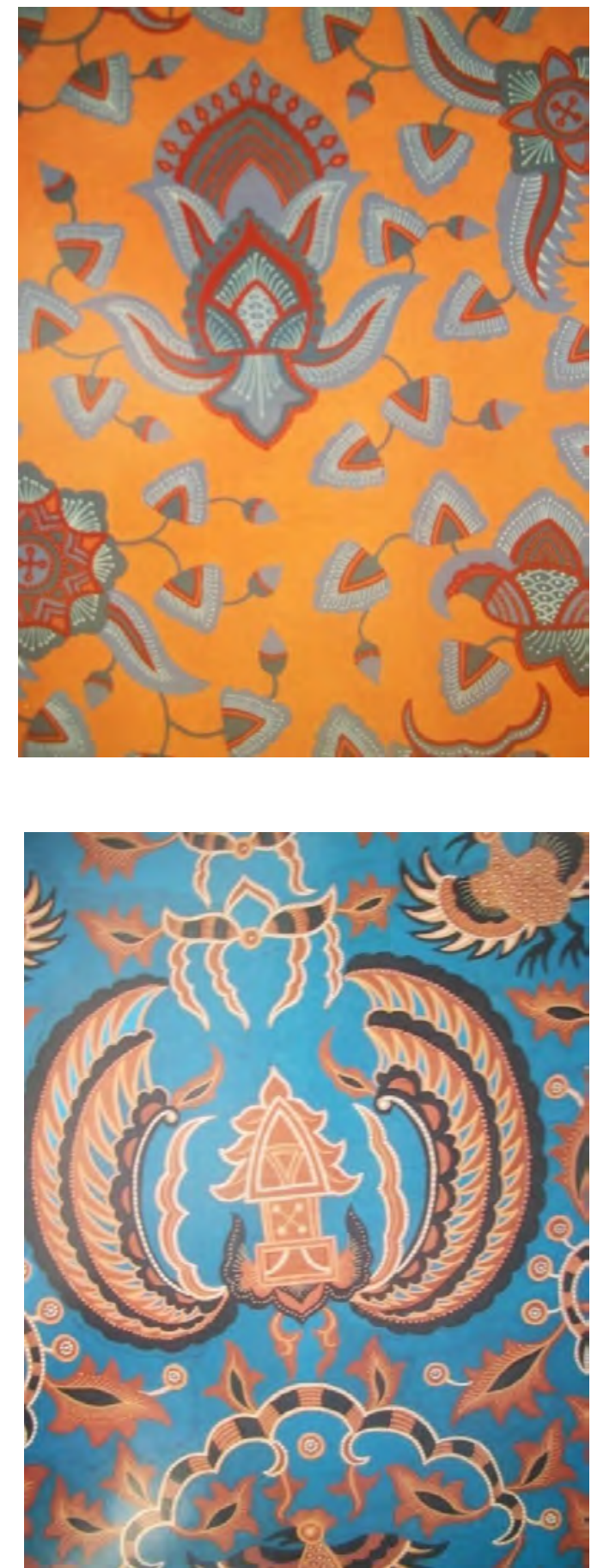

Gambar 22. Desain Batik Jadi ke-6

Merupakan hasil pengembangan dari motif Gegot dan batik Sido Mukti 


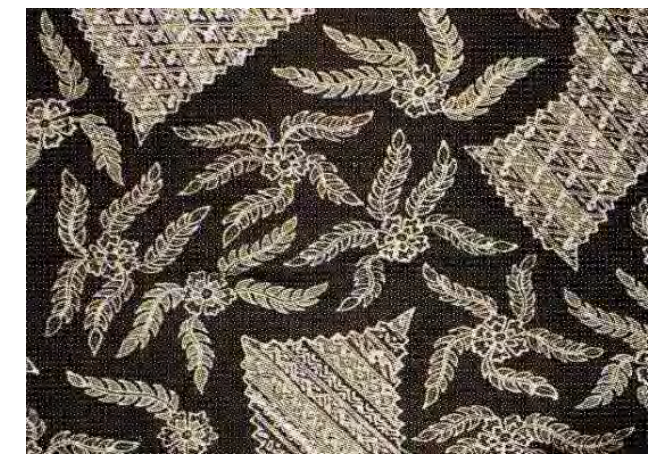

Gambar 24. Desain Batik Jadi ke-7 Merupakan hasil pengembangan dari motif Taru Polo
Gambar 23. Motif Taru Polo
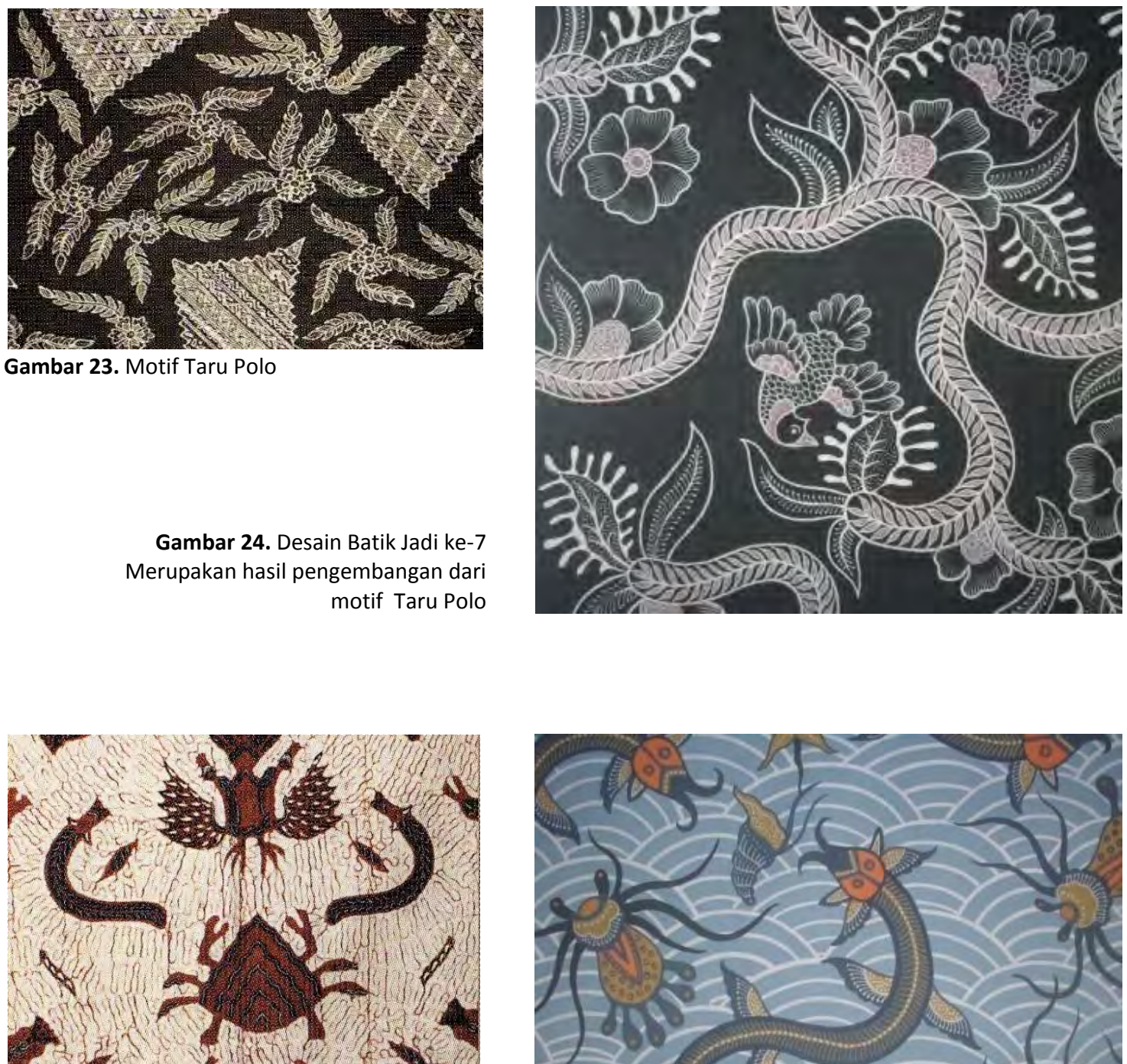

Gambar 25. Motif Mintuna Sogan

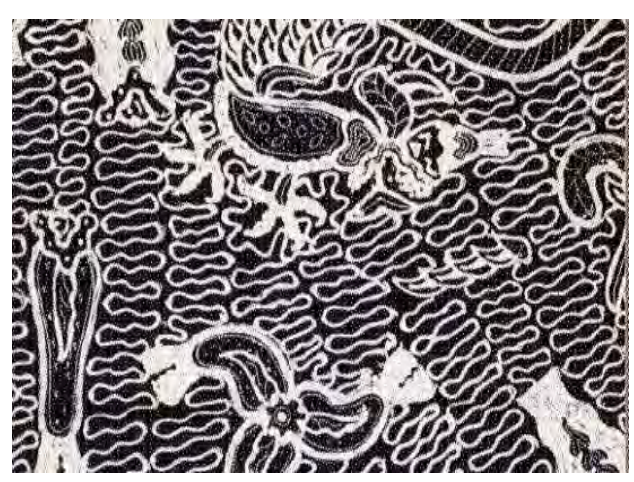

Gambar 26. Motif Mintuna

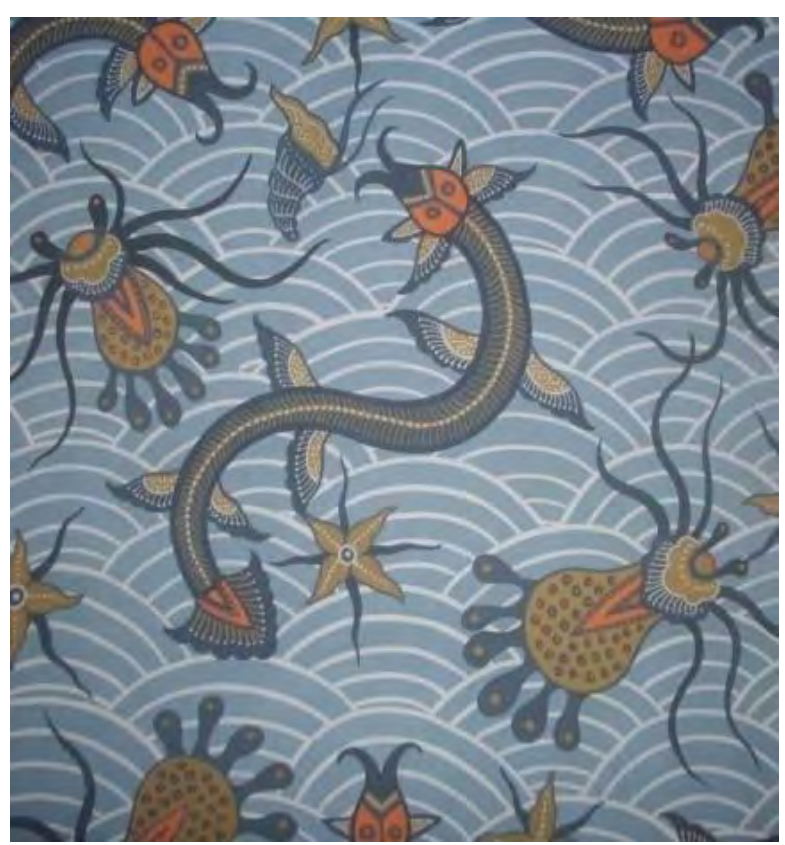

Gambar 27. Desain Batik Jadi ke-8

Merupakan hasil pengembangan dari motif Mintuna 


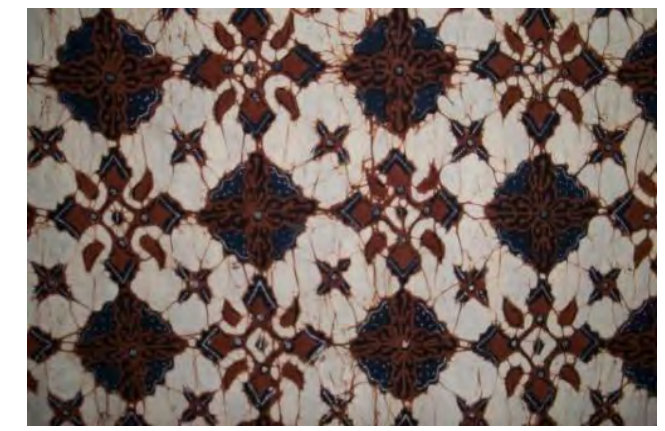

Gambar 34. Motif Srinuding

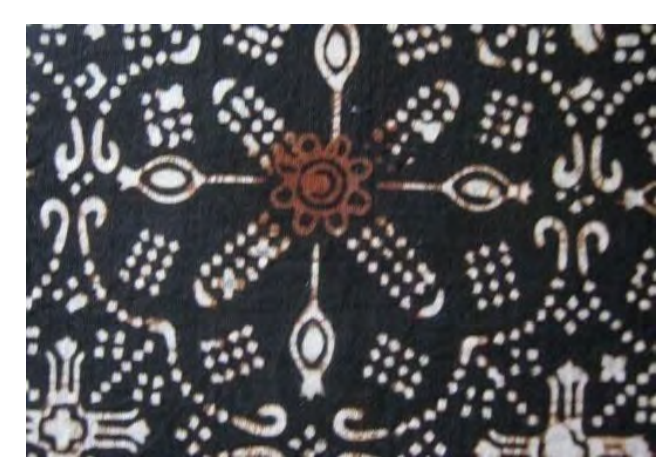

Gambar 35. Motif Nitik

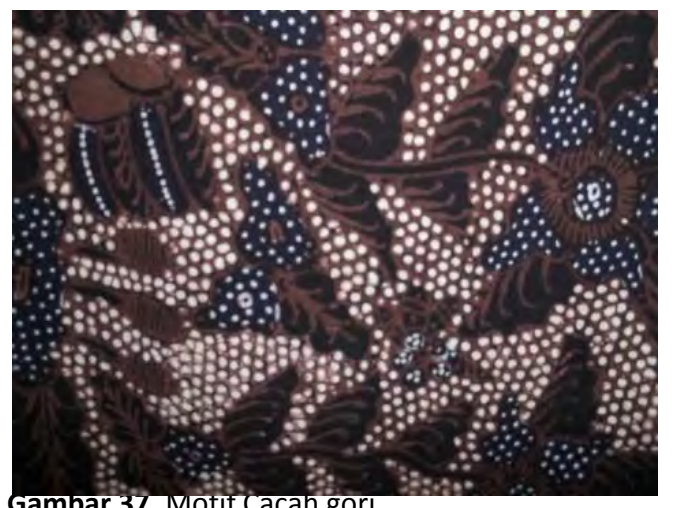

Gambar 38. Desain Batik Jadi ke-12 Merupakan hasil pengembangan dari motif Cacah Gori

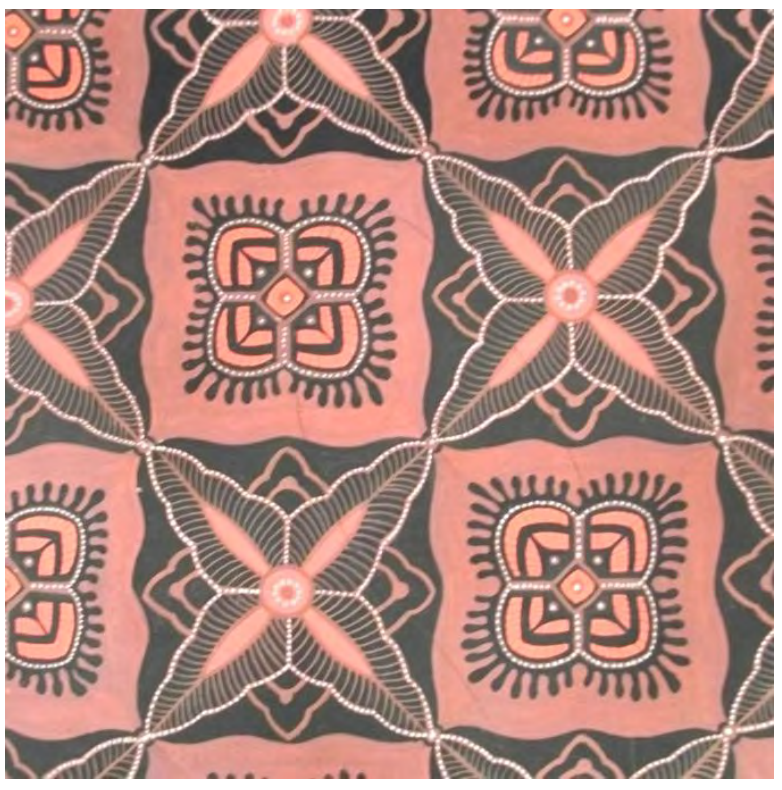

Gambar 36. Desain Batik Jadi ke-11

Merupakan hasil pengembangan dari motif Srinuding dan Nitik

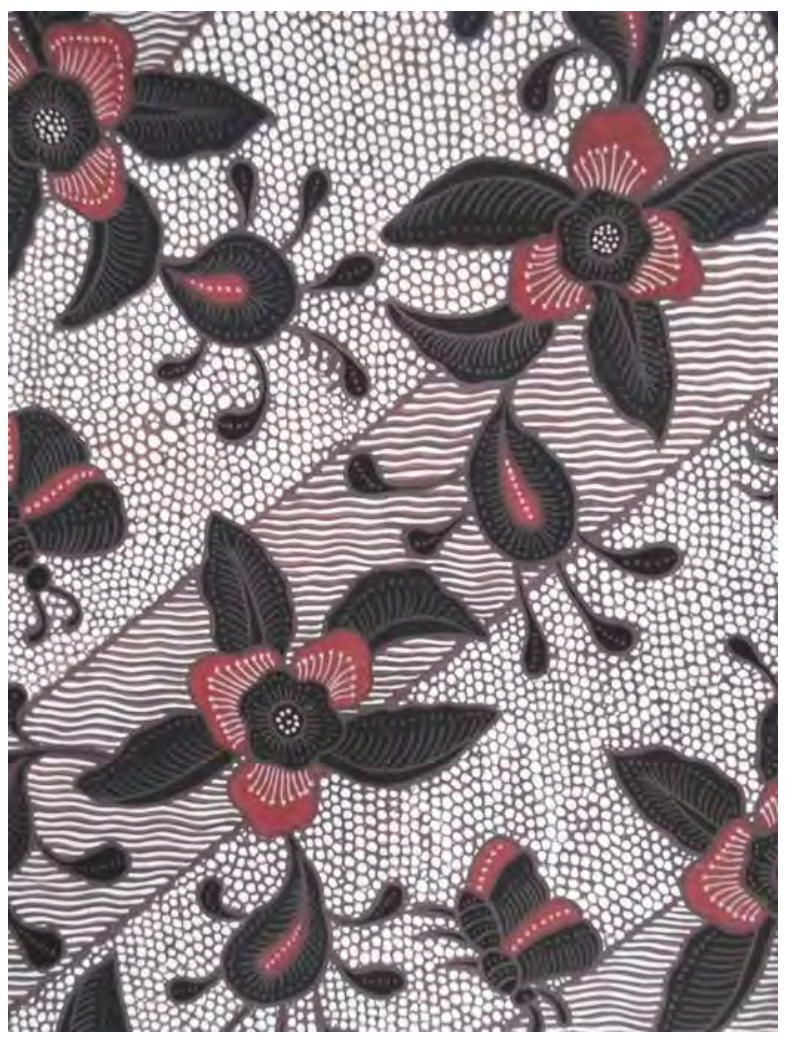




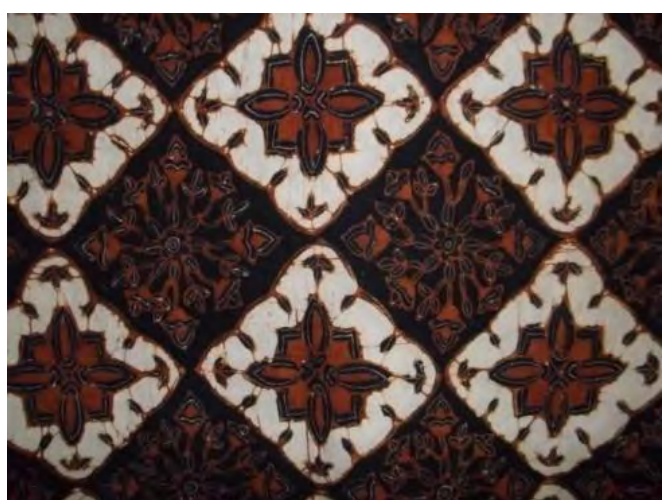

Gambar 50. Motif Probonegoro

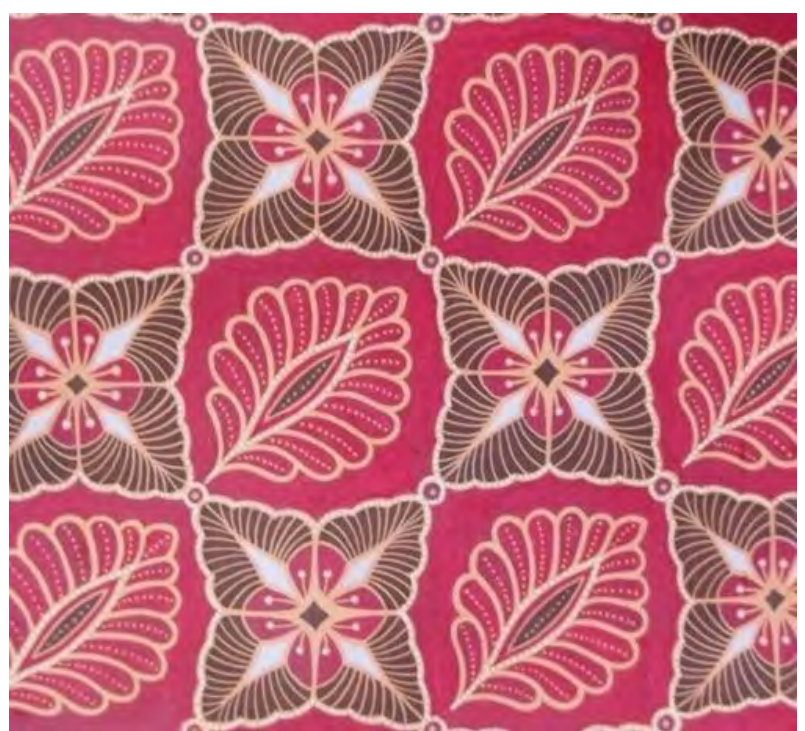

Gambar 51. Desain Batik Jadi ke-18

Merupakan hasil pengembangan dari motif Probonegoro

\section{KESIMPULAN}

Seni tradisional adalah kesenian asli yang lahir dengan adanya dorongan emosi dan kehidupan batin yang murni atas dasar pandangan hidup dan kepentingan pribadi masyarakat pendukungnya. Perkembangannya tergantung pada kondisi sosial budaya setempat dan persentuhan dengan masyarakat pendukung, serta pengaruh lingkungannya. Membatik di Bantul merupakan kegiatan produktif yang dilakukan sebagian masyarakat Bantul sebagai sumber mata pencaharian. Kegiatan membatik di Bantul tentu juga mengalami perkembangan dan perubahan baik fungsi, gaya, struktur, makna dan teknik, sesuai dengan arus perkembangan zaman. Perubahan itu dapat kita lihat pada pengertian masyarakat tentang ketidakpahaman akan ciri khas motif dari daerah Bantul.

Sejalan dengan perubahan zaman, batik mbantulan mengalami perkembangan yang dipicu oleh beberapa faktor. Pertama, faktor eksternal seperti adanya akulturasi, permintaan konsumen, berkembangnya ilmu pengatahuan, teknologi, dan industri pariwisata. Kemajuan ilmu pengetahuan dan teknologi merupakan faktor pendorong perkembangan seni batik ke arah pembaharuan, baik desain maupun pada peningkatan kwalitas. Munculnya mesin cap dalam batik dan kemajuan teknis lainnya yang berpengaruh terhadap perkembangan diversifikasi produk seni batik.

Penemuan batik cap dan pewarna sintetis dalam proses pembuatan batik membawa perubahan total dalam seluruh kegiatan batik. Batik bukan lagi menjadi pekerjaan golongan perempuan akan tetapi mulai banyak melibatkan kaum laki-laki. Dari kegiatan batik yang bersifat rumahan mulai beranjak pada industri batik/pabrik batik. Keuntungan dari batik cap adalah dapat memproduksi lebih banyak dari pada dikerjakan dengan tangan dan dapat juga dilakukan bersamaan. Hasilnyapun lebih memiliki nilai ekonomis dan tidak memakan waktu yang lama.

Kedua, faktor internal seperti tuntutan memenuhi kebutuhan hidup masyarakat Bantul dan para pengrajin batik pada khususnya, sehingga kegiatan 
membuat produk seni batik menjadi mata pencaharian pokok. Semakin tinggi tingkat penguasaan teknik keterampilan seorang pembatik, sangat berpengaruh terhadap kwalitas karya yang dihasilkan. Pengrajin tidak berbeda dengan seniman lainnya yang memiliki ekspresi pribadi. Ekspresi pribadi tersebut berpengaruh terhadap hasil karya seni batik yang dihasilkan. Ekspresi itu juga tercermin pada keseriusan, kehalusan, kerumitan karya yang dihasilkan dengan teknik dalam seni batik untuk melestarikan batik mbantulan agar tetap berkesinambungan.

Kedudukan seni batik mbantulan sebagai salah satu local genius sangat memegang peranan penting. Demikian pentingnya sehingga harus ada kesadaran yang melekat dimana kepeduliaan masyarakat penyangga seni batik pada umumnya dan batik mbantulan khususnya untuk melakukan revitalisasi. Revitalisasi ini harus mendapat perhatian yang saling terkoordinasi antara masyarakat, lembaga pendidikan, dan pemerintah setempat. Seni batik mbantulan memegang peranan sentral, yang eksistensinya merupakan roh atau spirit yang telah ikut menentukan warna kepribadian masyarakatnya.

\section{DAFTAR PUSTAKA}

Djoko Suryo, 1985, Gaya Hidup Masyarakat Jawa di Pedesaan: Pola Kehidupan Sosial Ekononomi dan Budaya, Departemen Pendidikan dan Kebudayaan Direktorat Jenderal Kebudayaan, Jakarta

Djomena, Nian S., (1990), Batik dan Mitra, Penerbit Djambatan, Jakarta

Doellah, Santoso, (2002), Batik Pengaruh Zaman dan Lingkungan, Danar Hadi, Surakarta
Elliot, Inger McCabe, (2004), Batik Fabled Cloth of Java, Published by Periplus Edition, Singapore

Herusatoto, Budiono, 2001, Simbolisme Dalam Budaya Jawa, Hanindita Graha Widia, Yogyakarta

Jenkins, Richard, 1992, Membaca Pikiran Pierre Bourdieu, 2004, Kreasi Wacana, Yogyakarta

Kamajaya, 1985, Serat Centhini (Suluk Tambangraras) Yasandalem Kanjeng Gusti Adipati Anom Mangkunegara (Ingkang Sinuwun Paku Buwana V ing Surakarta) Transliterasi latin, Yayasan Centhini, Yogyakarta

Koentjaraningrat, 1987, Kebudayaan, Mentalitas dan Pembangunan, Gramedia, Jakarta

Nurdjanti, Nunung, 2006, Jaringan Makna Tradisi Hingga Kontemporer, Kenangan Purna Bakti untuk Prof. Soedarso SP., M.A., BP ISI Yogyakarta

Padmapoespita, K.J., 1966, Pararaton, Penerbit Taman Siswa, Yogyakarta

Ronald, Arya, 2005, Nilai-nilai Arsitektur Rumah Tradisional Jawa, Gadjah Mada University Press, Yogyakarta

Sariyatun, 2005, Usaha Batik Masyarakat Cina Di Vorstenlanden Surakarta Awal Abad XX, Sebelas Maret University Press, Surakarta

Setiawati, Puspita, 2004, Kupas Tuntas Teknik Proses Membatik, Penerbit Absolut, Yogyakarta

Susanto, Sewan, 1973, Seni Kerajinan Batik Indonesia, Balai Penelitian Batik dan Kerajinan, Lembaga Penelitian 
Pendidikan Industri, Departeman Perindustrian RI, Jakarta

Suyanto, 1992, Tata Warna dan Teknik Pembuatan Batik Tradisional, Makalah disampaikan dalam Seminar Batik Tradisional Indonesia tanggal 6 Agustus 1992, STSI Surakarta

Tambunan, Tulus T.H., 2002, Usaha Kecil dan Menengah di Indonesia: Beberapa Isu Penting, Salemba Empat, Yogyakarta
Riyantono, dkk (Tim Peyusun), 2010, Batik Bantul, Pemerintah Daerah Kabupaten Bantul, Bantul

Van Der Hoop, A.N.J. a Th., 1949, Indonesische Siermotieven (Ragamragam Perhiasan Indonesia), Koninklijk Bataviaasch Genootschap Van, Kunsren En Wetenschappen

Zaenudin, Imam Buchori, 1986, Peranan Desain Dalam Peningkatan Mutu Produk, dalam Paradigma Desain Indonesia, Rajawali, Bandung 